\title{
Detecção de Staphylococcus spp. Coagulase Negativa em Cabras Lactantes para Monitoramento da Qualidade do Leite
}

Fernanda Rodrigues Lima da Costa ${ }^{1}$, Isabelle Franco ${ }^{2}$, Nara Patrícia Cavalcanti ${ }^{3}$, Daniel Maia Nogueira ${ }^{4}$, Mateus Matiuzzi da Costa ${ }^{5}$

Resumo: A caprinocultura leiteira tem aumentado sua participação na agropecuária brasileira e o mercado consumidor está cada vez mais exigente por produtos de qualidade. Esse trabalho teve como objetivo pesquisar a frequência de Staphylococcus spp. coagulase negativa na linha de produção de leite de cabras, criadas em sistema de pastejo irrigado na região semi-árida do Nordeste brasileiro. Foram analisadas 168 amostras de leite de cabras em lactação de uma propriedade em Santa Maria da Boa Vista no estado de Pernambuco. Estas foram processadas no laboratório de Microbiologia e Imunologia Animal da UNIVASF. Das amostras de leite analisadas, observou-se Staphylococcus spp. coagulase negativa em 45 (26,78\%), sendo que 40 (88,88\%) destas foram identificadas como $S$. epidermidis e cinco $(11,11 \%)$ como $S$. caprae. Foram consideradas portadoras de mastite $35(41,66 \%)$ das 84 cabras selecionadas, sendo $25(71,42 \%)$ unilateral e $10(28,57 \%)$ bilateral. Todas as amostras demonstraram sensibilidade a ciprofloxacina e norfloxacina, sendo que 97,8\% a nitrofurantoína, $93,4 \%$ a ceftriaxona, $86,9 \%$ a oxacilina, $82,6 \%$ a gentamicina, $71,7 \%$ a sulfametoxazol, $54,3 \%$ a lincomicina $41,3 \%$ a tetraciclina, $36,9 \%$ a ampicilina, $32,6 \%$ a neomicina e $23,9 \%$ penicilina $\mathrm{G}$. Este estudo demonstra a prevalência de Staphylococcus spp. coagulase negativo de casos de mastite subclínica em rebanhos leiteiros de cabras. Os antimicrobianos mais eficazes nos testes de sensibilidade in vitro foram a ciprofloxacina e a norfloxacina.

Palavras-chave: antimicrobianos, prevalência, tratamento

\section{Negative Coagulase Staphylococcus spp. in Lactant Goats to Milk Quality Evaluation}

Abstract: The culture of goat milk has increased its participation in the Brazilian farming and cattle raise and the consumer market is demanding more quality products. The present work aims to determine the prevalence of coagulase negative in a milk goat farm in nordestine semi-arid. We analyzed 168 milk samples of a farm from Santa Maria da Boa Vista in Pernambuco state. The samples were processed in the Animal Microbiology and Immunology Laboratory at UNIVASF. Coagulase negative Staphylococcus spp. were isolated from 45 (26,78\%) milk samples, being 40 (88,88\%) S. epidermidis and five (11,11\%) S. caprae. Thirty five (41,66\%) goats presented subclinical mastitis, being $25(71,42 \%)$ unilateral mastitis and 10 (28,57\%) bilateral mastitis. Every bacterial isolates were susceptible to ciprofloxacin and norfloxacin, 44 (97,8\%) to nitrofurantoin, $(93,4 \%)$ to ceftriaxone, $(86,9 \%)$ to oxacilin, $(82,6 \%)$ to gentamicin, $(71,7 \%)$ to sulfametoxazol, $(54,3 \%)$ to lincomicin, $(41,3 \%)$ to tetracicline, $(36,9 \%)$ to ampiciline, $(32,6 \%)$ to neomicine and $(23,9 \%)$ to penicilin

\footnotetext{
${ }^{1}$ Graduanda em Zootecnia/UNIVASF

${ }^{2}$ Mestranda em Ciência Animal nos Trópicos/UFBA. Bolsista CAPES

${ }^{3}$ Mestranda em Ciência Animal/UNIVASF

${ }^{4}$ Pesquisador da Embrapa Semi-árido

${ }^{5}$ Professor Adjunto I/UNIVASF. E-mail: mateus.costa@univasf.edu.br (autor para correspondência)
} 
G. Our study showed that coagulase negative Staphylococcus spp. were associated to subclinical mastitis in goats. The difference observed in susceptibility patterns indicated the importance of diagnostic tests and antimicrobial susceptibility tests to implement a correct treatment.

Key words: antimicrobials, prevalence, treatment

\section{Introdução}

A caprinocultura leiteira tem aumentado sua participação na agropecuária brasileira. $\mathrm{Na}$ região Nordeste, a maior parte da produção visa à subsistência, entretanto, o mercado consumidor está cada vez mais exigente por produtos de qualidade, os quais estão diretamente relacionados com o nível tecnológico da produção, a saúde do rebanho e dos ordenhadores (Contreras et al., 1999).

A mastite é o processo inflamatório da glândula mamária considerada uma das principais doenças que acometem os rebanhos de caprinos leiteiros, associada a perdas na produção e prejuízos econômicos ao produtor e à indústria (Fonseca \& Santos, 2000). A infecção é causada por vários microrganismos, particularmente de origem bacteriana entre os quais se destacam os Staphylococcus spp. coagulase positiva e negativa, S. epidermidis, S. caprae, Streptococcus agalactiae, S. dysgalactiae e Corynebacterium bovis, além de agentes ambientais como as enterobactérias. O diagnóstico da mastite pode ser realizado na propriedade por meio de testes como o CMT (California Mastitis Test) e o Whiteside (Quinn et al., 1994). Os objetivos desse trabalho foram identificar a presença de Staphylococcus spp. coagulase negativa no leite caprino como forma de monitoramento da qualidade desse produto e determinar o perfil de sensibilidade dos isolados aos antimicrobianos.

\section{Material e Métodos}

Este trabalho foi realizado no Laboratório de Microbiologia e Imunologia da Universidade Federal do Vale do São Francisco(UNIVASF). Foram utilizadas
84 cabras clinicamente sadias das raças Saanen, Pardo Alpina e Mestiça, sendo analisadas 168 amostras de leite de diferentes períodos de lactação provenientes de uma propriedade em Santa Maria da Boa Vista - PE.

Duas amostras de leite de cada animal (uma de cada teto) foram coletadas em frascos estéreis pela manhã, após os procedimentos de higiene pré-ordenha. As amostras foram acondicionadas em caixas isotérmicas a $4^{\circ} \mathrm{C}$ até sua chegada no laboratório, onde foi realizado o teste whiteside. Em seguida, foram semeadas em Ágar Sangue ovino a $5 \%$ e incubadas a $37^{\circ} \mathrm{C}$ por 24/48 horas. A identificação dos microrganismos foi realizada de acordo com características morfotintoriais (Quinn et al., 1994).

O perfil de sensibilidade dos isolados bacterianos pelo método de difusão em disco Kirby-Bauer modificado. Os fármacos avaliados foram: tetraciclina $(30 \mu \mathrm{g})$, ciprofloxacina $(05 \mu \mathrm{g})$, gentamicina $(10 \mu \mathrm{g})$, ampicilina $(10 \mu \mathrm{g})$, norfloxacina $(10 \mu \mathrm{g})$, oxacilina $(01 \mu \mathrm{g})$, ceftriaxona $(30 \mu \mathrm{g})$, lincomicina $(02 \mu \mathrm{g})$, nitrofurantoína $(300 \mu \mathrm{g})$, sulfametoxazol $(25 \mu \mathrm{g})$, neomicina $(30 \mu \mathrm{g})$ e penicilina $\mathrm{G}(10 \mathrm{U} . \mathrm{I})$. Os isolados foram semeados em caldo Müller Hinton e incubados durante $8 \mathrm{~h}$ a $37^{\circ} \mathrm{C}$ até obtenção da turvação conforme escala 0,5 de MacFarland, sendo semeados em placas de ágar Müller Hinton. Em seguida, foram adicionados os discos de antimicrobianos e as placas foram incubadas por 24 horas a $37^{\circ} \mathrm{C}$. Após a leitura dos halos foi determinado o perfil de sensibilidade dos isolados aos antimicrobianos.

\section{Resultados e Discussão}

Os resultados do teste whiteside revelaram que $23,8 \%$ dos animais avaliados eram portadores de 
Rev. Cient. Prod. Anim., v.12, n.1, p.98-101, 2010

mastite subclínica. Resultados semelhantes a estes foram demonstrados por (González-Rodríguez \& Cármenes, 1996), no qual o percentual de amostras negativas para o crescimento bacteriano foi aproximado aos resultados negativos no teste de Whiteside. Das amostras de leite analisadas, observou-se Staphylococcus spp. coagulase negativa em 45 (26,78\%) delas, sendo que 40 destes isolados $(88,88 \%)$ foram identificados como S. epidermidis e cinco $(11,11 \%)$ como $S$. caprae. Foram consideradas portadoras de mastite 35 (41,66\%) das 84 cabras, sendo que 25 delas $(71,42 \%)$ apresentaram mastite unilateral e 10 (28,57\%) bilateral (Tabela 1). Segundo Poutrel (1984) esses microrganismos possuem maior ocorrência em cabras e ovelhas leiteiras, ocasionando infecções subclínicas persistindo por alguns meses, até o período seco (Poutrel, 1984).

Todas as amostras bacterianas analisadas foram sensíveis a ciprofloxacina $(5 \mu \mathrm{g})$ e norfloxacina $(10 \mu \mathrm{g})$. A sensibilidade dos isolados para nitrofurantoína $(300 \mu \mathrm{g})$ foi de $97,8 \%$; 93,4\% para ceftriaxona $(30 \mu \mathrm{g})$; $86,9 \%$ para oxacilina $(1 \mu \mathrm{g}) ; 82,6 \%$ para gentamicina $(10 \mu \mathrm{g}) ; 71,7 \%$ para sulfametoxazol $(25 \mu \mathrm{g}) ; 54,3 \%$ para lincomicina $(2 \mu \mathrm{g}), 41,3 \%$ para tetraciclina $(30$ $\mu \mathrm{g}) ; 36,9 \%$ para ampicilina $(10 \mu \mathrm{g}) ; 32,6 \%$ para neomicina $(30 \mu \mathrm{g})$ e $23,9 \%$ para Penicilina G (10U.I) (Figura 1). A realização do teste de sensibilidade aos antimicrobianos é de extrema importância do rebanho.

Tabela 1 - Prevalência de Staphylococcus caprae e S. epidermidis em caprinos leiteiros de acordo com o padrão racial

\begin{tabular}{llcccc}
\hline \multicolumn{1}{c}{ Microrganismo } & Raças & $\begin{array}{c}\mathrm{N}^{0} \text { de } \\
\text { cabras }\end{array}$ & Unilateral & Bilateral & $\begin{array}{c}\text { Prevalência } \\
\text { de mastite }(\%)\end{array}$ \\
\hline S. caprae & Saanen & 03 & 03 & - & $3,57(03 / 84)$ \\
S. epidermidis & Alpina & 07 & 04 & 03 & $8,33(07 / 84)$ \\
& Mestiça & 07 & 06 & 01 & $8,33(07 / 84)$ \\
S. caprae + S. epidermidis & Saanen & 16 & 12 & 04 & $19,04(16 / 84)$ \\
& Alpina & 01 & - & 01 & $1,19(01 / 84)$ \\
Animais negativos & Mestiça & 01 & - & 01 & $1,19(01 / 84)$ \\
& Alpina & 20 & - & - & $23,80(20 / 84)$ \\
Total & Mestiça & 08 & - & - & $9,52(08 / 84)$ \\
& Saanen & 21 & - & - & $25(21 / 84)$ \\
\hline
\end{tabular}




\section{Literatura Citada}

CONTRERAS, A., J. C. CORRALES, A. SANCHEZ, AND D. SIERRA. Persistence of caprine intramammary pathogens throughout lactation. J. Dairy Sci. 80:2815-2819, 1997.

FONSECA, L. F. \& SANTOS, M. V. Qualidade do leite e controle de mastite. São Paulo: Lemos Editorial, p.175, 2000.

GONZÁLEZ-RODRÍGUEZ,M.C.\& CÁRMENES, QUINN, P.J., CARTER, M.E., MARKEY, B., P. Evaluation of the California mastitis test as a CARTER, G.R. Clinical veterinary Medicine, discriminant method to detect subclinical mastitis London: Mosby-Year, p.648, 1994. 